\title{
Electroless Fabrication of Cobalt Alloys Nanowires within Alumina Template
}

\author{
Nazila Dadvand ${ }^{1}$ and Georges J. Kipouros ${ }^{2}$ \\ ${ }^{1}$ Industrial Materials Institute, National Research Council Canada, Surface Technology Group, Boucherville, Quebec, Canada J4B 6Y4 \\ ${ }^{2}$ Materials Engineering Programme, Department of Process Engineering and Applied Science, Dalhousie University, Halifax, \\ Nova Scotia, Canada B3J 2 X4
}

Received 19 December 2006; Revised 12 May 2007; Accepted 30 May 2007

Recommended by Zhili Xiao

\begin{abstract}
A new method of nanowire fabrication based on electroless deposition process is described. The method is novel compared to the current electroless procedure used in making nanowires as it involves growing nanowires from the bottom up. The length of the nanowires was controlled at will simply by adjusting the deposition time. The nanowires were fabricated within the nanopores of an alumina template. It was accomplished by coating one side of the template by a thin layer of palladium in order to activate the electroless deposition within the nanopores from bottom up. However, prior to electroless deposition process, the template was pretreated with a suitable wetting agent in order to facilitate the penetration of the plating solution through the pores. As well, the electroless deposition process combined with oblique metal evaporation process within a prestructured silicon wafer was used in order to fabricate long nanowires along one side of the grooves within the wafer.
\end{abstract}

Copyright (C) 2007 N. Dadvand and G. J. Kipouros. This is an open access article distributed under the Creative Commons Attribution License, which permits unrestricted use, distribution, and reproduction in any medium, provided the original work is properly cited.

\section{INTRODUCTION}

In recent years considerable efforts have been made to design and fabricate nanostructured materials. The interest in nanoscale materials arises from properties related to their size, composition, structural order, and surface functionalization. Among nanostructured materials, nanowires are promising for many novel applications, ranging from chemical and biological sensors to optical and electrical devices [1-6]. This is because of their unique geometry and many unique physical properties including electrical, magnetic, optical, and mechanical properties [7-9]. Magnetic nanowires are important magnetic nanostructures due to their potential applications in ultra-high-density magnetic recording, high-frequency sensors and other devices $[10,11]$.

To date, most efforts have been focused on development of better methods for fabricating nanowires and their characterization [12]. A widely used method is based on various templates, including positive, surface step edge, and negative templates [13-15]. In positive template methods wire-like nanostructure such as DNAs and carbon nanotubes are used as templates and nanowires are formed on the outer surface of the template. Therefore, the diameters of the nanowires are not limited by the template sizes and can be controlled by adjusting the amount of deposited materials. In surface stepedge template method, atomic-scale step edges on a crystal surface are used as templates for growing of nanowires. The growth process is based on the fact that material deposition on a surface often begins preferentially at defect sites such as surface step edges. Finally, in negative template methods, prefabricated cylindrical nanopores are used in a solid material as templates and nanowires are fabricated by material deposition into the nanopores. The material deposition inside the nanopores can be done by several methods which among them, the electrodeposition process is the most versatile method. In comparison with electrodeposition, the electroless deposition method of nanowire fabrication has advantages. For example, it requires no power supply or electroplating tank. As well, in electroless process, the metal deposition proceeds uniformly down the entire length of the nanopores.

The electroplating method requires more sophisticated instrumentation, like a rectifier, which is usually preferably used in a pulse plating mode and there are other important parameters to be considered such as current density and pulse characteristics. Therefore, the whole process, in electrodeposition, is more difficult to control. With electrochemical deposition, tubular structures cannot be fabricated 
as the growth of nanowires proceeds from the bottom up. In electroplating, very high metal-salt concentration is used in order to avoid the competing hydrogen evolution reaction as much as possible.

To our knowledge, there are no reports on using electroless deposition process as a possible chemical deposition method for bottom-up fabricating the nanowires of amorphous alloys such as CoFeB and CoFeP. The bottom-up electroless deposition allows fabricating of nanowires with a desired length simply by adjusting the deposition time. The nanowire fabrication based on electroless process that has been described in literature [16-19] is not a bottom-up type process and involved exposing the template into a sensitizing/activating solution, which results in metallic deposition on the template faces and pore walls during the plating. Therefore, after short deposition times, a hollow metallic tubule is obtained within each pore, while long deposition times result in solid metal wire. However, if the deposition reaction proceeds too fast, the pores may be blocked at the template surface before the tubule or fiber growth can be completed. As well, the process yields structures that run the complete thickness of the template. Therefore, the length of the metallic nanowires cannot be controlled at will. Development of a bottom-up electroless deposition may solve the above-mentioned problem [20].

The current work presents a method of nanowire fabrication within the pores of an alumina template to overcome the above-mentioned limitations. Specific examples of fabrication of $\mathrm{Co}_{x} \mathrm{Fe}_{y} \mathrm{~B}_{z}$, a soft magnetic nanowire arrays which is of interest for high frequency sensor applications are described. Soft magnetic $\mathrm{Co}_{x} \mathrm{Fe}_{y} \mathrm{P}_{z}$ nanowires fabrication will be presented in an article to be submitted soon.

\section{EXPERIMENTAL}

The porous alumina template (Anopore, obtained from Whatman Company) was approximately $50 \mu \mathrm{m}$ in thickness, and $200 \mathrm{~nm}$ in pore diameter. The pore densities was as high as $10^{10}$ pores $/ \mathrm{cm}^{2}$.

The adsorption of 5-sulfosalicylic acid and 1,2dihydroxy-3,5-benzenedisulfonic acid disodium salt (Tiron) on alumina template was measured at various $\mathrm{pH}$. An amount of $10^{-6} \mathrm{~mol}$ of Tiron per $\mathrm{m}^{2}$ of alumina template was added into a solution of $10^{-2} \mathrm{M} \mathrm{NaCl}$. The $\mathrm{pH}$ of the solution was adjusted using $\mathrm{NaOH}$ and $\mathrm{HCl}$ and the alumina template was then soaked into the solution for 24 hours at $50^{\circ} \mathrm{C}$. The solution containing the immersed alumina template was then transferred into a Bokhner filter. The template was rinsed on filter with distilled water and the filtrate was collected. The $\mathrm{pH}$ of the filtrate containing nonadsorbed Tiron was adjusted to $\mathrm{pH}$ 4. The filtrate was then transferred into a volumetric flask followed by addition of distilled water to make the solution volume up to $100 \mathrm{ml}$. The quantity of non-adsorbed Tiron in filtrate was then measured using uv-vis spectrophotometer. The quantity of the adsorbed Tiron was calculated by subtracting the amount of the non-adsorbed Tiron from the initial value. The adsorbtion was measured at the wavelength related to OH group in Tiron $(\lambda=290 \mathrm{~nm})$.

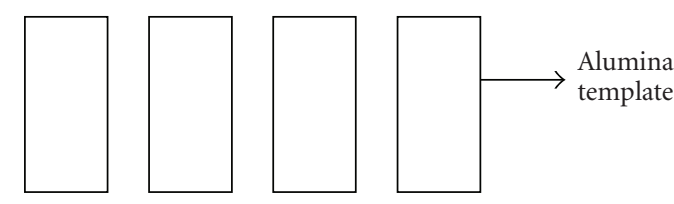

(a)

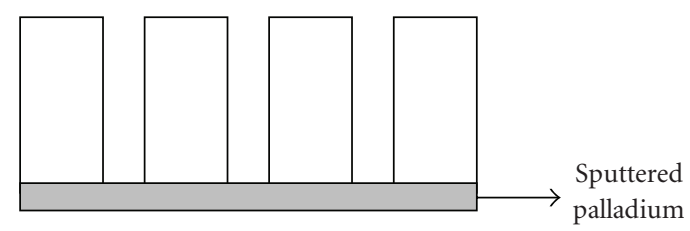

(b)

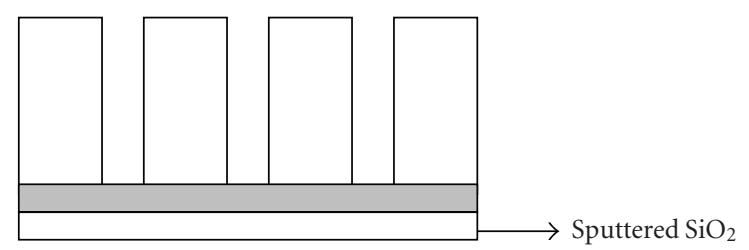

(c)

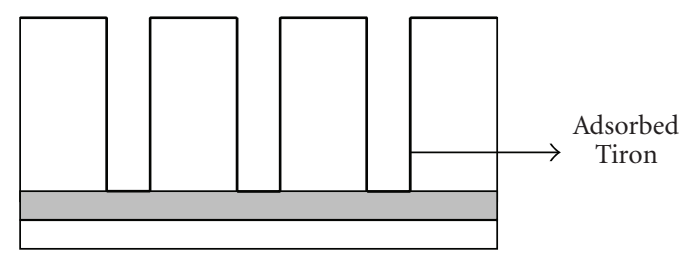

(d)

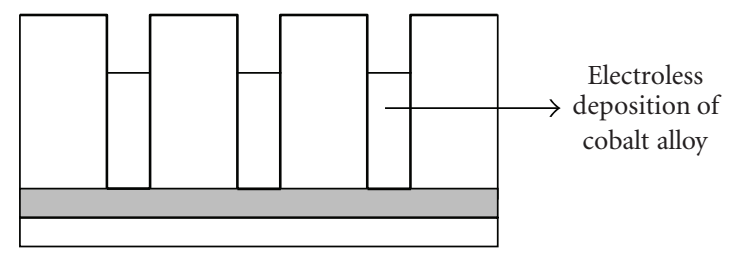

(e)

FIGURE 1: Schematic diagram of nanowire fabrication based on electroless deposition process: (a) alumina template; (b) sputter deposition of palladium layer on one face of alumina template; (c) deposition of $\mathrm{SiO}_{2}$ on palladium layer via electron beam evaporation process; (d) treatment of alumina template with Tiron; (e) electroless deposition of cobalt alloys within the nanopores.

Nanowire fabrication within the pores of alumina template was accomplished by sputter deposition of one face of the fabricated alumina template with a $2 \mu \mathrm{m}$ layer of palladium followed by $\mathrm{SiO}_{2}$ deposition through electron beam evaporation process. The template was then treated with Tiron: it was immersed into a solution containing $10^{-2} \mathrm{M}$ $\mathrm{NaCl}$ and $10^{-6} \mathrm{~mol}$ of Tiron per $\mathrm{m}^{2}$ of alumina for 24 hours at $50^{\circ} \mathrm{C}$. The $\mathrm{pH}$ of the solution was adjusted to $\mathrm{pH} 4$ using $\mathrm{NaOH}$ and $\mathrm{HCl}$. The template was then taken out of the solution, rinsed with distilled water, and exposed to electroless plating solution. The fabrication process is shown in Figure 1. 


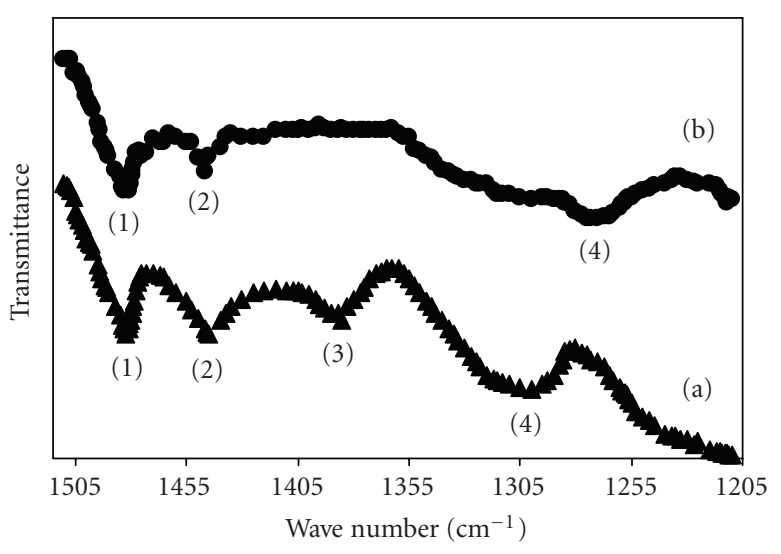

Figure 2: FT-IR spectra of (a) pure Tiron; (b) Tiron-treated alumina template.

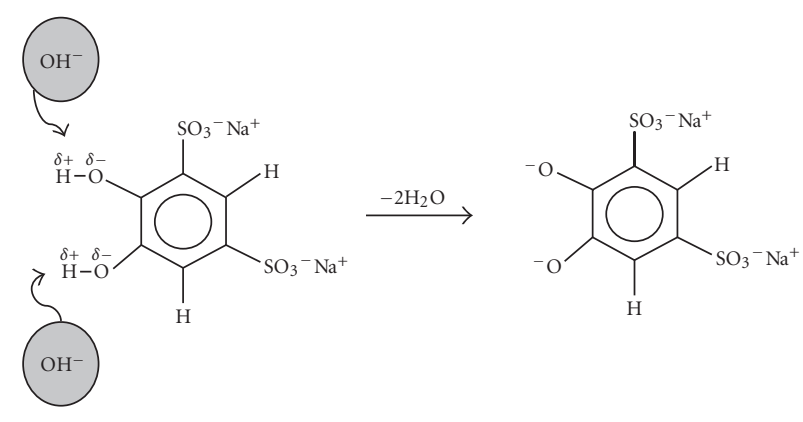

(a)

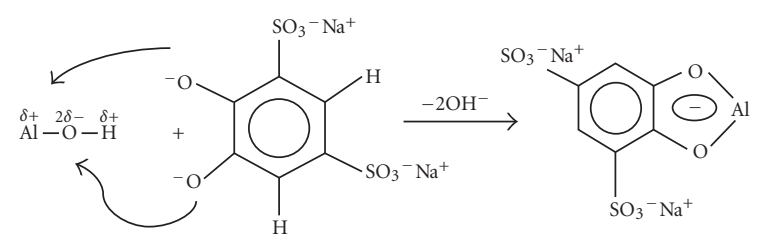

(b)

FIgURE 3: Interaction of alumina with Tiron: (a) dissociation of Tiron molecule in alkaline solution; (b) complex formation between alumina and dissociated Tiron molecule.

The electroless plating solution contained cobalt (II) sulfate heptahydrate $(0.06 \mathrm{M})$ as a source of cobalt ions; iron (II) sulfate heptahydrate $(0.01 \mathrm{M})$ as a source of iron ions; dimethylaminoborane (DMAB, $0.26 \mathrm{M})$ as a reducing agent and boron source; sodium tartrate $(0.2 \mathrm{M})$ and sodium citrate $(0.05 \mathrm{M})$ as complexing agents; ammonium sulfate $(0.2 \mathrm{M})$ as a buffering agent; phosphorous acid $(0.06 \mathrm{M})$ as a slow-rate reducing agent, and thallium acetate $(1.06 \times$ $10^{-4} \mathrm{M}$ ) as stabilizer. The $\mathrm{pH}$ of solution was adjusted to $\mathrm{pH}$ 6.5 using a concentrated solution of sodium hydroxide and the operating temperature was maintained at $348 \pm 1 \mathrm{~K}$ with a thermostatically controlled water bath.

In order to determine the cobalt, iron, and boron contents of the deposited cobalt alloy from the electroless cobalt plating solution that was used for fabricating of nanowires,

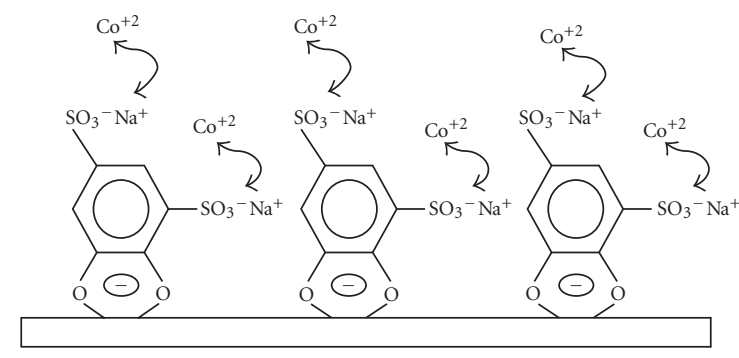

FIgURE 4: Schematic diagram of the Tiron-treated alumina surface.

a pure copper substrate (99.5\%) was cleaned by immersion into heptane at $40^{\circ} \mathrm{C}$ for 10 minutes. It was then sensitized by immersion into a solution of $\mathrm{SnCl}_{2}\left(0.1 \mathrm{~g} \cdot \mathrm{l}^{-1}\right)$ and $\mathrm{HCl}$ $\left(0.1 \mathrm{~g} \cdot \mathrm{l}^{-1}\right)$ at room temperature for 3 minutes followed by rinsing with distilled water and immersion into a solution of $\mathrm{PdCl}_{2}\left(0.1 \mathrm{~g} \cdot \mathrm{l}^{-1}\right)$ and $\mathrm{HCl}\left(0.1 \mathrm{~g} \cdot \mathrm{l}^{-1}\right)$ at room temperature for 3 minutes. The activated copper substrate was then rinsed with distilled water and exposed to the electroless plating solution for 2 hours under the same conditions as those used for nanowire fabrication. The plated cobalt alloy was then stripped off the substrate by dissolving into a mixture of hydrogen peroxide and nitric acid $(1: 8 \mathrm{v} / \mathrm{v})$. The dissolved cobalt alloy was then analyzed for cobalt, iron, and boron using inductively coupled plasma (ICP) [21].

A Hitachi S-4700 scanning electron microscope (SEM) operating at $15 \mathrm{kV}$ was used to obtain a micrograph of fabricated nanowires within the alumina template.

\section{RESULTS AND DISCUSSION}

The fabrication process of cobalt alloys nanowires was based on using an activating layer of palladium on one face of the alumina template. The side of deposited palladium layer facing the nanopores catalyzed the electroless deposition of cobalt alloys inside the pores. Therefore, the nanopores were filled with cobalt alloys from bottom up. In order to protect the opposite side of the palladium layer from electroless deposition of cobalt alloys, it was covered by $\mathrm{SiO}_{2}$ layer via electron beam evaporation.

The template was pre-treated prior to electroless deposition process to facilitate the penetration of the plating solution through the nanopores. The pretreatment process involved cleaning and removing any trapped air from the nanopores through solvent cleaning and ultrasonic agitation, and presoaking in suitable wetting agent such as Tiron. The effect of Tiron as a wetting agent on suspension of alumina particles has been reported [22-25]. The interaction between the Tiron molecules and alumina surface was studied using FT-IR spectroscopy. Figure 2 displays the FT-IR spectra for pure Tiron and Tiron-treated alumina template. The peaks assigned as 1,2, and 4 are related to benzene ring characteristic vibrations and peak 3 is related to in-plane bending vibration of $\mathrm{O}-\mathrm{H}$ functional group. In Tiron-treated alumina spectrum, peak 3 was absent indicating the coordination of 


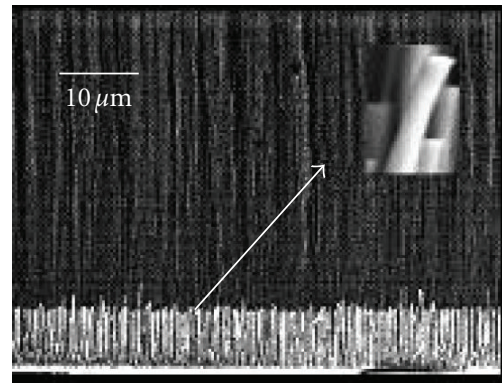

(a)

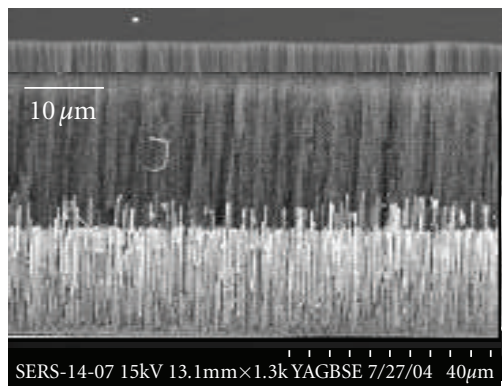

(d)

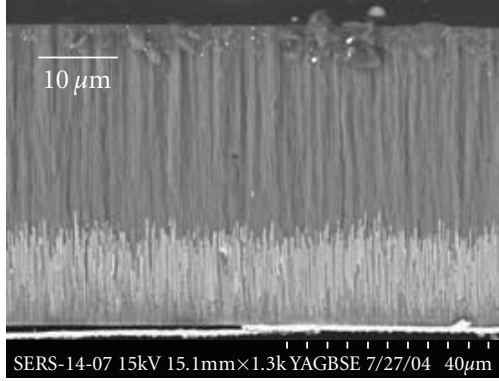

(b)

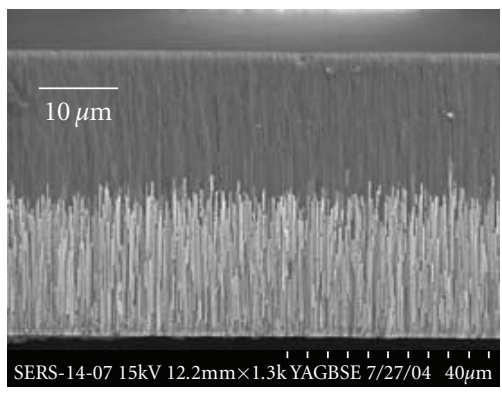

(e)

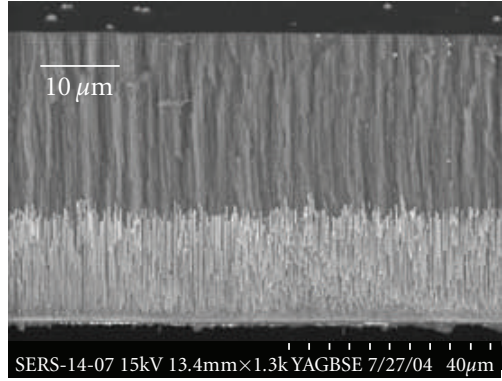

(c)

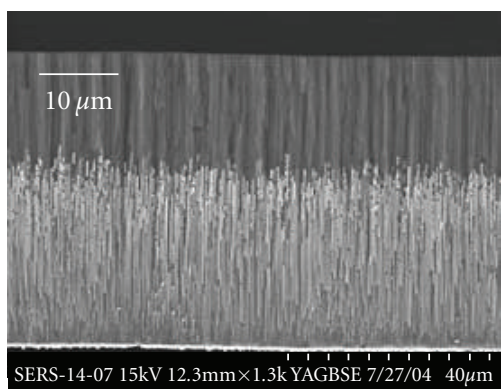

(f)

FIgURE 5: Electroless deposition of $\mathrm{Co}_{90} \mathrm{Fe}_{3} \mathrm{~B}_{7}$ nanowires within the nanopores of alumina template at various deposition times: (a) 45minute deposition time. The nanowires are $10 \mu \mathrm{m}$ in length and $200 \mathrm{~nm}$ in diameter; (b) 1-hour and 33-minute deposition time. Nanowires are $25 \mu \mathrm{m}$ in length and $200 \mathrm{~nm}$ in diameter; (c) 2-hour and 15-minute deposition time; (d) 3-hour deposition time; (e) 3-hour and 45minute deposition time; (f) 4-hour and 30-minute deposition time.

the two oxygen atoms of Tiron molecule to $\mathrm{Al}^{3+}$ ion hence disappearing the $\mathrm{O}-\mathrm{H}$ groups in Tiron.

The complex formation reaction between the surface of alumina template and Tiron is displayed in Figure 3. As it can be seen, Tiron molecule dissociates in alkaline solution producing the anion that goes into coordination reaction with the aluminum ion and produces an alumina-Tiron complex compound. In fact, the ortho-position of $\mathrm{OH}$ groups in Tiron molecules favors the formation of a stable inner complex compound.

Figure 4 shows a schematic diagram of the Tiron-treated alumina surface. As it can be seen, after the treatment, the surface of alumina template is covered by Tiron molecules. Each molecule carries two $\mathrm{SO}_{3}^{-}$anions and two $\mathrm{Na}^{+}$cations. The sodium cations then undergo cationic exchange reaction with the cobalt ions in electroless cobalt plating solution producing complex compounds between the cobalt and the adsorbed Tiron molecules. The tendency of the reaction towards the cobalt-Tiron complex formation stimulates the migration of the cobalt ions from the bulk towards the electrode surface hence enhancing the solution penetration into the nanopores.

Figure 5 shows SEM micrograph of nanowires fabricated within the nanopores of alumina template at various deposition times. As it can be seen, varying the deposition time controlled the length of nanowires due to the bottom-up nature of the growing process.
The electroless deposition method of nanowire fabrication was combined with oblique metal evaporation within a pre-structured silicon wafer template and nanowires of cobalt alloys were grown along the grooves within the silicon wafer. Oblique angle deposition basically combines a typical deposition system with a tilted and rotating substrate. Figure 6 displays the fabrication process based on oblique metal evaporation method. An electron beam evaporation system was used to deposit metal at an angle onto a prestructured substrates such as V-grooved silicon wafer. When the samples were aligned properly with respect to the evaporation source, only one of the slide planes was exposed to the highly directional beam of metal atoms. The angle between the incident beam and the substrate normal determined the area of the side plane covered with metal. Thus by tuning $\theta$ the width of the wires can be controlled. A sample holder to position the substrates at different $\theta$ was used to make samples with different line widths in a single evaporation run. Using the angle-evaporation technique, thin strips of palladium nanowires were formed in the location of interest on a pre-structured wafer followed by electroless deposition process. Palladium strips catalyzed electroless deposition and nanowires began to grow where palladium exists.

Figure 7 shows an array of $10 \mathrm{~nm}$ wide $\mathrm{Pd}$ wires that was obtained by evaporating of palladium at $\theta=45^{\circ}$ followed by $15 \mathrm{~nm}$ silicon dioxide angle evaporation at $\theta=70^{\circ}$. The $\mathrm{Pd}$ wires were running along one side of the grooves. Electroless 


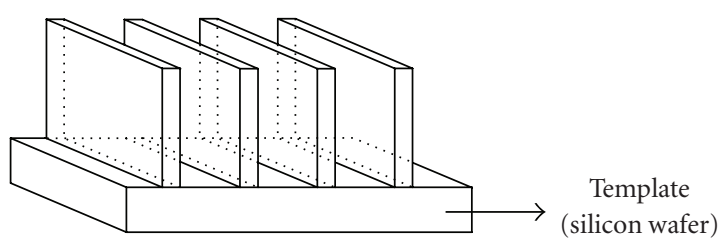

(a)

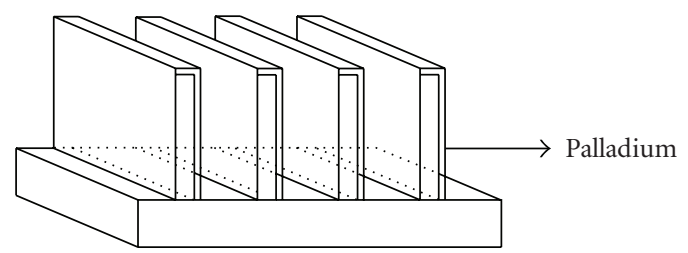

(b)

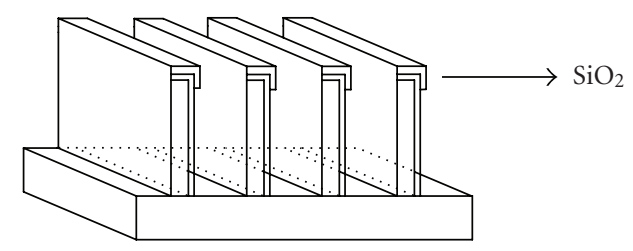

(c)

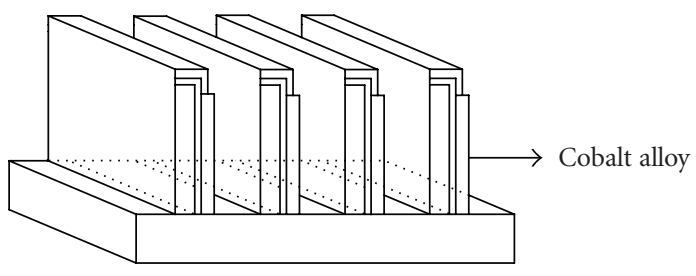

(d)

Figure 6: Nanowire fabrication using oblique metal evaporation and electroless deposition: (a) silicon wafer; (b) palladium angleevaporation on silicon wafer; (c) silicon dioxide angle-evaporation on silicon wafer; (d) electroless deposition of $\mathrm{Co}-\mathrm{Fe}-\mathrm{B}$.

deposition of $\mathrm{Co}-\mathrm{Fe}-\mathrm{B}$ began where the palladium was not covered by silicon dioxide.

\section{CONCLUSION}

Electroless deposition was used as a chemical deposition method for bottom-up fabrication of amorphous cobalt alloys nanowires within the nanopores of a synthesized alumina template. The method allowed growing of nanowires with a desired length simply by adjusting the deposition time. It was accomplished by sputter deposition of one face of the template of a thin layer of palladium as a catalyst. The side of palladium layer that was not facing the nanopores of the template was covered with an inert material such as $\mathrm{SiO}_{2}$ in order to prevent depositing cobalt alloy on this side of the film during the nanowire fabrication.

In order to facilitate the penetration of the plating solution through the pores, the template was treated with a suitable wetting agent such as Tiron. Following the treat-

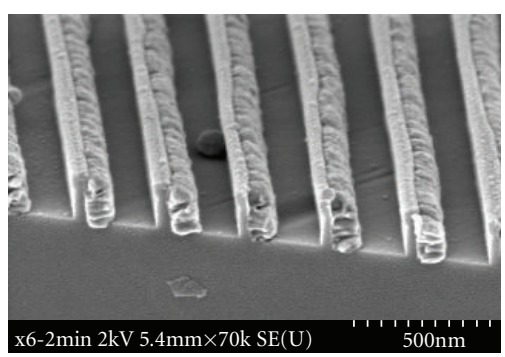

FIgURE 7: SEM micrograph of $\mathrm{Co}-\mathrm{Fe}-\mathrm{B}$ nanowires within prestructured silicon wafer.

ment, the surface of alumina template is covered by Tiron molecules. Each molecule carries two $\mathrm{SO}_{3}^{-}$anions and two $\mathrm{Na}^{+}$cations. The sodium cations then undergo cationic exchange reaction with the cobalt ions in electroless cobalt plating solution producing complex compounds between the cobalt and the adsorbed Tiron molecules. The tendency of the reaction towards the cobalt-Tiron complex formation stimulates the migration of the cobalt ions from the bulk towards the electrode surface hence enhancing the solution penetration into the nanopores.

The electroless deposition combined with oblique metal evaporation within a pre-structured silicon wafer was successfully used to fabricate long nanowires along one side of the grooves within the wafer. Using the angle-evaporation technique, thin strips of palladium nanowires were formed in the location of interest on a pre-structured wafer followed by electroless deposition process. The palladium strips catalyzed electroless deposition and nanowires began to grow where palladium was present.

\section{ACKNOWLEDGMENTS}

The Authors would like to thank Dr. Bo Cui from Functional Nanomaterials group for performing oblique metal evaporation and providing the prestructured silicon wafers. The authors would also like to thank Mr. Michel Thibodeaujrom Surface Technology group for taking SEM micrographs.

\section{REFERENCES}

[1] F. Favier, E. C. Walter, M. P. Zach, T. Benter, and R. M. Penner, "Hydrogen sensors and switches from electrodeposited palladium mesowire arrays," Science, vol. 293, no. 5538, pp. 22272231, 2001.

[2] E. C. Walter, F. Favier, and R. M. Penner, "Palladium mesowire arrays for fast hydrogen sensors and hydrogenactuated switches," Analytical Chemistry, vol. 74, no. 7, pp. 1546-1553, 2002.

[3] J. Handley, "Stretching the wire frontier," Analytical Chemistry, vol. 74, no. 7, pp. 196A-199A, 2002.

[4] R. Dagani, Chemical \& Engineering News, vol. 79, pp. 14-18, 2001.

[5] B. R. Martin, D. J. Dermody, B. D. Reiss, et al., "Orthogonal self-assembly on colloidal gold-platinum nanorods," Advanced Materials, vol. 11, no. 12, pp. 1021-1025, 1999. 
[6] R. M. Dickson and L. A. Lyon, "Unidirectional plasmon propagation in metallic nanowires," Journal of Physical Chemistry $B$, vol. 104, no. 26, pp. 6095-6098, 2000.

[7] L. Piraux, J. M. George, J. F. Despres, et al., "Giant magnetoresistance in magnetic multilayered nanowires," Applied Physics Letters, vol. 65, no. 19, pp. 2484-2486, 1994.

[8] S. Dubois, C. Marchai, J. M. Beuken, et al., "Perpendicular giant magnetoresistance of $\mathrm{NiFe} / \mathrm{Cu}$ multilayered nanowires," Applied Physics Letters, vol. 70, no. 3, pp. 396-398, 1997.

[9] A. Blondel, J. P. Meier, B. Doudin, and J.-P. Ansermet, "Giant magnetoresistance of nanowires of multilayers," Applied Physics Letters, vol. 65, no. 23, pp. 3019-3021, 1994.

[10] X. Xu and G. Zangari, "Microscopic structure and magnetic behavior of arrays of electrodeposited $\mathrm{Ni}$ and Fe nanowires," Journal of Applied Physics, vol. 97, no. 10, Article ID 10A306, 3 pages, 2005.

[11] M. Hernández-Vélez, K. R. Pirota, F. Pászti, D. Navas, A. Climent, and M. Vázquez, "Magnetic nanowire arrays in anodic alumina membranes: rutherford backscattering characterization," Applied Physics A, vol. 80, no. 8, pp. 1701-1706, 2005.

[12] C. R. Martin, R. Parthasarathy, and V. Menon, "Template synthesis of electronically conductive polymers-a new route for achieving higher electronic conductivities," Synthetic Metals, vol. 55, no. 2-3, pp. 1165-1170, 1993.

[13] H. He and N. J. Tao, "Electrochemical fabrication of metal nanowires," Encyclopedia of Nanoscience and Nanotechnology, vol. 2, pp. 755-772, 2003.

[14] S. Fullam, D. Cottell, H. Rensmo, and D. Fitzmaurice, "Carbon nanotube templated self-assembly and thermal processing of gold nanowires," Advanced Materials, vol. 12, no. 19, pp. 14301432, 2000.

[15] A. Brodde, G. Wilhelmi, D. Badt, H. Wengelnik, and H. Neddermeyer, "The growth of Ag films on $\mathrm{Ni}(100)$," Journal of Vacuum Science \& Technology B, vol. 9, no. 2, pp. 920-923, 1991.

[16] M. Wirtz and C. R. Martin, "Template-fabricated gold nanowires and nanotubes," Advanced Materials, vol. 15, no. 5, pp. 455-458, 2003.

[17] M. Barbic, J. J. Mock, D. R. Smith, and S. Schultz, "Single crystal silver nanowires prepared by the metal amplification method," Journal of Applied Physics, vol. 91, no. 11, pp. 93419345, 2002.

[18] H. Zhang, X. Ma, J. Xu, J. Niu, J. Sha, and D. Yang, "Directional CdS nanowires fabricated by chemical bath deposition," Journal of Crystal Growth, vol. 246, no. 1-2, pp. 108-112, 2002.

[19] C. J. Brumlik, V. P. Menon, and C. R. Martin, "Template synthesis of metal microtubule ensembles utilizing chemical, electrochemical, and vacuum deposition techniques," Journal of Materials Research, vol. 9, no. 5, pp. 1174-1183, 1994.

[20] N. Dadvand, R. Menini, and T. Veres, "Effect of tiron on electroless fabrication of nanowires within alumina templates," in Proceedings of the 207th Meeting of the Electrochemical Society (ECS '05), p. 89, Quebec City, Canada, May 2005.

[21] N. Dadvand, G. Jarjoura, and G. J. Kipouros, "Preparation and characterization of $\mathrm{Co}-\mathrm{Fe}-\mathrm{B}$ thin films produced by electroless deposition," Journal of Materials Science: Materials in Electronics, in print.

[22] L. Jiang, L. Gao, and Y. Liu, "Adsorption of salicylic acid, 5sulfosalicylic acid and Tiron at the alumina-water interface," Colloids and Surfaces A, vol. 211, no. 2-3, pp. 165-172, 2002.

[23] L. Jiang and L. Gao, "Effect of Tiron adsorption on the colloidal stability of nano-sized alumina suspension," Materials Chemistry and Physics, vol. 80, no. 1, pp. 157-161, 2003.
[24] R. Laucournet, C. Pagnoux, T. Chartier, and J. F. Baumard, "Catechol derivatives and anion adsorption onto alumina surfaces in aqueous media: influence on the electrokinetic properties," Journal of the European Ceramic Society, vol. 21, no. 7, pp. 869-878, 2001.

[25] C. R. Evanko, R. F. Delisio, D. A. Dzombak, and J. W. Novak Jr., "Influence of aqueous solution chemistry on the surface charge, viscosity and stability of concentrated alumina dispersions in water," Colloids and Surfaces A, vol. 125, no. 2-3, pp. 95-107, 1997. 

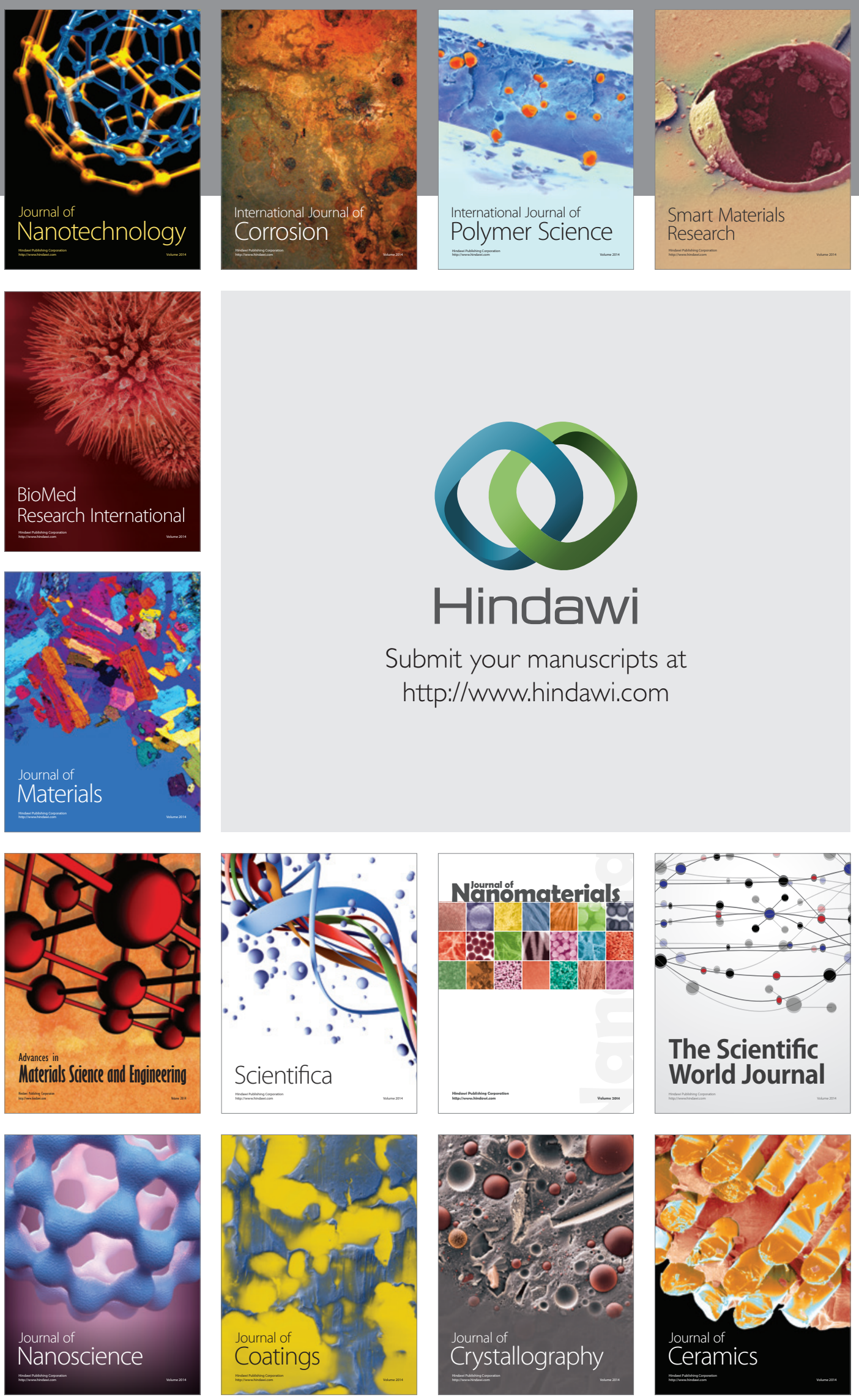

The Scientific World Journal

Submit your manuscripts at

http://www.hindawi.com

\section{World Journal}

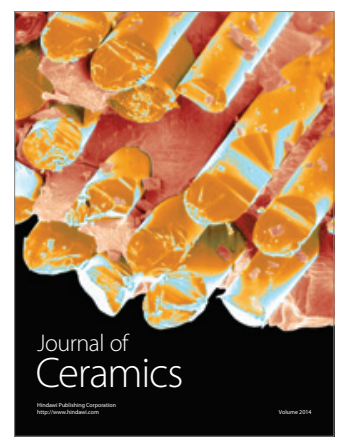

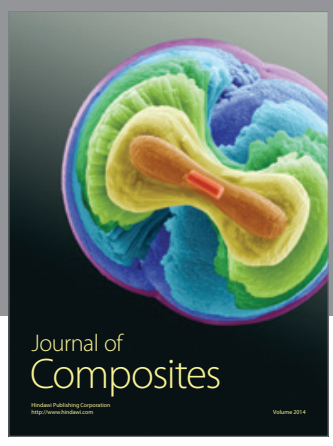
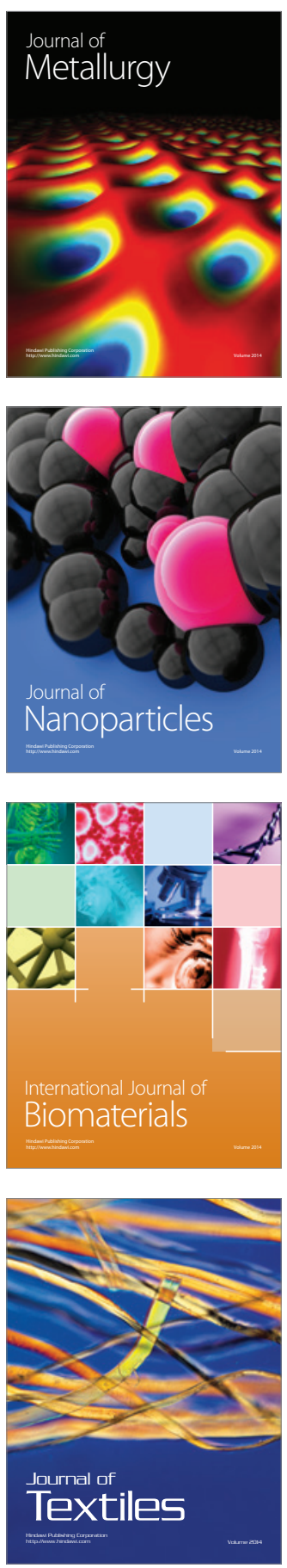